\title{
Regional Economic Development Model Toward Business Sustainability Support in Less Developed Countries
}

\author{
Ibrahim Krasniqi \\ Faculty of Business, Haxhi Zeka University, Peja, Kosovo \\ Email address: \\ ibrahim.krasniqi@unhz.eu,ik4616@g.rit.edu \\ To cite this article: \\ Ibrahim Krasniqi. Regional Economic Development Model Toward Business Sustainability Support in Less Developed Countries. Science \\ Journal of Business and Management. Vol. 7, No. 5, 2019, pp. 95-106. doi: 10.11648/j.sjbm.20190705.11
}

Received: July 24, 2019; Accepted: September 16, 2019; Published: September 26, 2019

\begin{abstract}
The research paper is mainly focusing on analysis and findings about the most suitable regional economic development models in less developed countries. Strategically the research is concentrated to find ways and build an approach toward balanced regional economic development (RED). During research the paper, specifically ifs focused to develop a strategic model for regional economic development in young country used as case study in the paper- Kosovo case. That model should be used to support the business environment as well affecting the overall development of the country through coordinated project management and synergy creation among the communities, local authorities and businesses. The research methodology used shows and mixed-methodological approach including both qualitative and quantitative data collection and appraisal, which included desk review covering existing literature at national and international level, semi-structured interviews with key, group discussions, relevant reports and other related documents. Actual situation in Kosovo regarding regional development suffers in many directions. Policies and strategies actually leave a gap, whilst most of regions and municipalities lack the capacities to create an effective environment for private sector development and job creation. There as well is dissatisfaction among stakeholders regarding the functioning of existing regional development model, structures and processes. The paper aims to establish new model and approach for balanced regional economic development based on balanced distribution of responsibilities between the central and local government levels with clear roles and responsibilities. This model will serve as one stop shop at regions supporting the business development and increasing employability in the country.
\end{abstract}

Keywords: Regional Economic Development Model, Strategic Management, Businesses Environment, Sustainability

\section{Introduction}

Regional economic development models, policy and practice have transformed significantly over the last decades. Their relevance has been challenged in recent years by the new economic geography that has emerged in view of globalization as most nations veer towards a more democratic and decentralized approach to plan and implement their various economic development activities. Modern growth theory has devoted substantial attention to the search for the determinants of economic growth by means of aggregated models. In these approaches 'economic development' has been often conceptualised as an increase in 'equilibrium' per-capita income and the interest of researchers mainly has concerned the identification of the main economic factors influencing it $[1,2]$. Given these advances, the emergence of new regional dynamics calls on countries to fine-tune current Regional Economic Development (RED) perspectives and/or to develop new strategies and approaches that are not only more in sync with the present and future global context and with the governance systems being adopted, but are also becoming more and more business oriented. Regional economics is the branch of economics which incorporates the dimension 'space' into analysis of the workings of the market. It does so by including space in logical schemes, laws and models which regulate and interpret the formation of prices, demand, productive capacity, levels of output and development, growth rates, and the distribution of income in conditions of unequal regional endowments of resources [2, 3].

In the case study the paper analysis small transition country-Kosovo as one of the poorest in Europe with a 
income per capita GDP $€ 3,332$ in 2017 and $€ 3,277$ in 2015 that shows slight increase. An unemployment rate of $31 \%$ and a youth unemployment rate near $60 \%$ in a country where the average age is 26 years old, encourages emigration and presents a significant source of informal, unreported economy. Most of Kosovo's population lives in rural area outside of the capital, Pristina. Inefficient, near-subsistence farming is common - the result of small plots, limited mechanization, and a lack of technical expertise. Kosovo enjoys lower labor costs than the rest of the region [12]. To design suitable strategies for the Regional Economic Development and for its effective implementation, the following aspects need to be focused upon:

a. A shared understanding on regional economic development across all levels of the government and private sectors.

b. The establishment of an agreed process for regional economic development activities, particularly at places where these activities would be implemented through common projects.

c. Strong cooperation and collaboration between governments and sectors, particularly with regard to co-investment and partnerships in regional economic development.

d. The establishment of incentives and rewards mechanisms for encouraging the most innovative, competitive, and productive regions.

e. The establishment of a dashboard for measuring the value generation and performance indicators for business and economic development at regional level.

The National Development Strategy 2016-2021, [16], aims to address the key obstacles in the overall development of Kosovo. These obstacles largely correspond with the obstacles faced in sustainable economic development and include the challenges encountered in the strategic vision, coordination of development policies and institutional processes, as identified by various national and international stakeholders.

Kosovo as young country is heavily depending on the donor's assistance and actually, most of this support is coming through the Instrument for Pre-accession Assistance (IPA). Under IPA, Kosovo has gained institutional support network with sub-granting to private sector and business development in the regions. This support has included institutional framework establishment that includes the establishment of five Regional Development Agencies (RDAs) and a coordinated support network for economic development (ARDA) located in the central level. This is in line with Kosovo's EU (European Union) accession policy related to EU Regional Economic Development Strategy and Policy, as well with structural funds provided. However, this regional economic development approach did not play well the role it has aimed. It especially concerns building capacities of national human resources and ensuring absorption of future financial support toward business development and private sector advancement. Thereof lessons learned from the previous financial assistance, have to be considered and translate in the future strategic steps for the regional economic development including:

a. The need for a more strategic and holistic approach to Regional Economic Development and further support in improving the business environment and infrastructure throughout Kosovo.

b. The need for revising the mechanism (RDAs, ARDA, and other related institutions) for managing and using financial resources available for economic development at regional and local level.

c. Most of the five established regions and municipalities have shown that they face serious problems in planning and managing projects as per the EU guidelines as well as in managing other development initiatives.

d. The need for a more intensive and continuous collaboration and cooperation at the regional level for consolidating and multiplying the individual efforts into a more effective tool for development.

In this context, the elaboration of an adequate strategy for Regional Economic Development is the basis for reducing regional disparities by supporting employment- and wealth/welfare-generating economic activities for the achievement of a balanced and sustainable regional development. Strategical management approach for the sustainable regional economic development in Kosovo reflects the challenges, problems, and shortcomings to be addressed for the purpose of approximation with the EU regional development strategies policies [7].

\section{Literature Review}

Any discussion on regional economic development cannot be divorced from the long debated issue on what economic development is in general and how it can be achieved. A number of the multitudinous theories and concepts of development that have been put forward in the past hundred years have significantly shaped regional economic development thinking.

Neoclassical economics became one of the important bases of regional development policies as it had been applied to the analysis of regional imbalances and the manner by which such problem can be resolved [14] While the classical economists have concerned themselves with the exploration of the formation, distribution and utilization of the national surplus, the "Neoclassicists" focused chiefly on the problem of resource allocation.

Richardson [9] explains the claim of neoclassical economics that regional disparities in terms of supply and demand of factors of production (labor, capital, technology) or commodities will even out inevitably given the sufficient increase in the accessibility between regions and consequently by the mobility of these production factors and commodities. According to the theory, regional imbalances in supply and demand manifest themselves in differences in prices of these factors of production and commodities. That is, prices will be low in region A if it has excess supply. In contrast, prices will be high in region $\mathrm{B}$ if it has excess 
demand. With perfect mobility of the production factors and commodities, these factors and commodities will move from regions of low prices to regions of high prices $[4,5]$. As a result, region A will have a diminished supply and therefore increased prices, while in region $\mathrm{B}$, supply will increase and cause prices to decline. Prices are, thus expected to converge towards an interregional equilibrium such that factor and commodity prices over the entire national territory are equal. This is important as the theory assumes that equal factor prices would lead to equal income levels [13]. The other view, so called balanced growth strategy and policy [20], argues that concentrating resources only in a few sectors especially those which have the absorptive capacity for modern technology would undermine the potentials of the other sectors [17]. This is especially in cases where the other sectors comprise the major component of the economy and particularly difficult in cases wherein the sectors are closely linked and interdependent that lifting one or few sectors would risk others to be neglected in the process. Those who argue against balance growth contends that the likely resources needed to implement large-scale and simultaneous investment efforts in a developing country may be found wanting [15].

Hirschman, A. O. [10] contention is that the inputs necessary for balance to occur such as capital, entrepreneurship, regulating policies and informational mechanisms on demand, supply and prices that are to be applied simultaneously within and among all the regions are very limited in underdeveloped countries. Thus, a better option given this consideration is to have a clear identification of strategically correct sequences of investments that would realize the greatest total linkages among these investments.

In the past decades, the use of clusters or clustering, networks and other related terms in regard of RED have emerged. The use of the term cluster has been popularized with the introduction of Porter's approach [19] in the term and in the context of competition of firms and locations. $\mathrm{He}$ defined a cluster to mean "a geographical proximate group of interconnected companies and associated institutions in a particular field, linked by commonalities and complementarities". He showed the significance of these inter industry linkages in the competitiveness of national (and regional) economies.

It is obvious that regional economic development tends to occur at the local level where interactions between economic agents are particularly dense. At the same time, socioinstitutional factors appear crucial for the creation of a local competitive advantage and make interactions work in a systemic way $[3,4]$.

However even in small countries like in Kosovo, not all locations are characterized by favorable conditions and we suggested that national growth is often led by few fastgrowing and innovative places within a country, mostly concentrated in a limited number of locations [3] suggesting that also there might be concentrated resources for innovation to succeed to translate knowledge into valuable economic activity [4] and regional economic development in general.

\subsection{Regional Economic Developments - Experiences}

In most countries, strategic management approach for regional economic development began in the period 1950s and 1960s. The post-war period of reconstruction was characterized by strong economic growth, fiscal expansion, and low unemployment. The principal objectives of regional policy were greater equity and balanced development during the period of rapid industrialization, which however was accompanied by increasing regional disparities. In the same period, the debate over regional development started and the research on the interdependencies of sectorial policies and the impacts on regions facilitated cooperation of crosssectorial policies [22]. Regional development reflects not merely the outcome of market forces, but also complex political, institutional, and cultural factors that shape how economic decisions are made. Following a long period during which regional policy was marginal, it has now become a more central policy element in many countries. Comprehensive regional policies increasingly find their role as complementary to national economic and structural policies by helping generate growth and wealth in the regions [13, 22]. Currently, Kosovo neither has a regional development policy nor a law on regional development and adequate strategies. In many countries, socio-economic disparities persist, though there are differences in intensity and in how these problems are perceived. In some countries, disparities are considered to be relatively limited and do not justify major regionally targeted interventions (e.g. Austria, Denmark, Luxembourg, and the Netherlands).

In some countries, severe inter-regional disparities remain or are even increasing. Policy responses to these disparities are divided into three categories:

i keeping the main policy focus on regional disparities (e.g. Germany and Italy);

ii providing support for lagging regions although it is not the main policy focus (e.g. Finland and Japan);

iii focusing on national economic growth in spite of internal disparities (e.g. Czech Republic and Hungary).

The traditional focus on inter-regional disparities has been complemented with more detailed intra-regional disparities, an urban-rural divide, and concern about the decline of distressed areas (e.g. old industrial areas, rural areas, urban poverty pockets), [1].

\subsection{Comparison to Other Countries}

In order to achieve balanced economic, social and territorial development, the EU Cohesion Strategic targets and strategic policy aims to reduce disparities between regions. Cohesion Policy finds its origins in the Treaty of Rome. The Treaty of Rome (1957), expresses the necessity to strengthen the unity of economies between EU countries and also emphasizes the need to ensure harmonious development of unequal regions by reducing the existing 
socio-economic differences and disparities among the regions. In addition, the Treaty of Lisbon and its economic reform strategy of Europe 2020 is focused on five key areas viz. employment, innovation, education, social inclusion and climate/energy provides that, in order to promote economic development, the European Union shall develop and pursue actions leading to strengthening of economic, social and territorial cohesion. In particular, the EU aims at reducing disparities among regions [3], The key areas are pursued under the umbrella of three mutually reinforcing priorities for the European Union to become an economy that are:

a. Smart;

b. Sustainable; and c. Inclusive.

The strategy to address the priorities and key areas has thus far pivoted around the concept of education and training. Kosovo has to adopt the most suitable strategies for RED based on good examples around and in EU [2].

The actual setup and mechanisms in various countries with some similarities with Kosovo are explained below with the aim to provide an overview on how the neighboring countries approach Regional Economic Development and how they face the challenge of a sustainable, balanced and smart development over whole their territories and business development.

Table 1. Regional economic development and institutional framework in different countries.

\begin{tabular}{|c|c|}
\hline $\begin{array}{l}\text { Northern } \\
\text { Macedonia }\end{array}$ & $\begin{array}{l}\text { Regional Development in Macedonia is based on the Law on Equal Regional Development, Equal Regional Development Strategy, and } \\
\text { Action Plan for each planning region. According to this Law, Macedonia has no territorial administrative regions but they are called } \\
\text { planning regions for the purpose of planning and implementation of regional development plans. There are eight regions that have } \\
\text { established centers for the Development of Planning Regions. }\end{array}$ \\
\hline Slovenia & $\begin{array}{l}\text { Since } 2000 \text {, Slovenia is divided into } 12 \text { statistical regions that are grouped into two cohesion regions and that replace the historical regions } \\
\text { of the country, which are East Slovenia consisting of Mura, Drava, Carinthia, Savinja, Central Slovenia and Southeast Slovenia; and West } \\
\text { Slovenia including Central Slovenia, Carniola, Gorizia, and coastal regions. The Ministry of Economic Development and Technology is } \\
\text { responsible for regional development and the legislation on equal/balanced regional development, preparation of the programme for } \\
\text { national development, and coordination of } 12 \text { programmes for regional development. }\end{array}$ \\
\hline Latvia & $\begin{array}{l}\text { Latvia has five planning regions corresponding to } 33 \text { regional local governments, } 26 \text { of which are counties and seven are republican Cities. } \\
\text { The planning regions of Latvia are not administrative territorial divisions and they are not mentioned in the law that prescribes the } \\
\text { administrative territorial divisions. The Ministry of Environmental Protection and Regional Development (MEPRD) is responsible for } \\
\text { regional development policy. Under the responsibility of the MEPRD, the State Regional Development Agency (SRDA) is the national } \\
\text { regulatory authority promoting regional development. It manages the state programmes and the activities of the EU Structural Funds. }\end{array}$ \\
\hline Estonia & $\begin{array}{l}\text { Estonian territory is divided into five regions. These are only for statistical and administrative purposes of the EU. There are } 15 \text { counties } \\
\text { which are regional units of state government with a total of } 241 \text { municipalities. The Minister for Regional Affairs within the Ministry of } \\
\text { Interior coordinates the regional policy. The Ministry of Interior is responsible for the design and implementation of regional policy in } \\
\text { cooperation with other ministries (Ministry of Economy, Ministry of Agriculture and Ministry of Environment), and for monitoring and } \\
\text { analysis of the regional development }\end{array}$ \\
\hline Croatia & $\begin{array}{l}\text { Croatia, an EU member since 2013, is structured into two regions, Continental Croatia including } 13 \text { counties and the city of Zagreb; and } \\
\text { the Adriatic Croatia including seven coastal counties. The Ministry of Regional Development and EU funds (MRDEUF) is responsible for } \\
\text { regional policy and operational plan for regional development. The Ministry participates in the preparation of priorities and annual and } \\
\text { long-term strategic and operational documents for the use of EU funds and other international sources and monitors the implementation of } \\
\text { measures and activities set out in strategic documents. Directorate for regional development, as an internal unit of the Ministry, is } \\
\text { responsible for a set of tasks related to regional development policy. }\end{array}$ \\
\hline Albania & $\begin{array}{l}\text { The National Strategy for Regional Development 2007-2013, aims at "a sustainable and balanced socio-economic growth between the } \\
\text { regions of Albania, in general, and mountainous and remote areas in particular, in order to support the rapid development of the whole } \\
\text { country and accelerate the process of integration into European Union membership." } \\
\text { With the Decree No. } 961 / 2015 \text {, the office of the Prime Minister established the National Agency for Regional Development, four Regional } \\
\text { Development Agencies, and the Agency for Regional Economic Development. } \\
\text { The Regional Development Fund (RDF) supports investments and projects at regional and local levels through a competitive grant system } \\
\text { in several policy areas where eligible applicants are local governments and development agencies. }\end{array}$ \\
\hline
\end{tabular}

\section{Methodology and Data Collection}

During this work the documentation required for the evaluation was provided by different institutions, and in some cases, the additional information was gathered during field visits. The stakeholders and respective institutions including RDAs were cooperative and they were systematically consulted and interviewed. The evaluation methodology primarily used a mixed approach based on qualitative and quantitative data collection and appraisal, which included:

a. Desk reviews of existing literature at national and international level.

b. Semi-structured Interviews with key stakeholders
(ARDA/RDAs, involved Ministries, municipalities and other relevant partners like NGOs, private sector, institutes and Chamber of Commerce).

c. Completion of data from semi-structured interviews and group discussions.

d. Regional development strategies.

e. Reports on business environment in Kosovo.

f. Grant materials and reports produced.

\subsection{Methodological Tools for Field Assessment}

The methodology used included both qualitative and quantitative approach, face-to-face meetings and interviews as well as primary and secondary data collection. The instruments and tools used include face-to-face discussions 
and semi-structured interviews as presented in the annex. The flow of the discussion is based on a strategic thinking approach. The interviews were divided in parts considering the perception and knowledge about the current situation in terms of what exists, how satisfied the stakeholders are with the actual model, what the modalities for improvement are, and what should be changed in the future. In the synthesis phase, the comprehensive analysis is prepared based on relevant information collected from literature, key informants, and stakeholders. In the desk review, the research was oriented in three directions:

a. Analysing all available documents relevant for the assignment.

b. Analysing the legal framework related to regional development in Kosovo.

c. Analysing the primary data taken from consultations and field work.

\subsection{Field Assessment}

Between January 2017 and April 2018, various consultation meetings were held with all stakeholders, have been organized consultations with line ministries, municipalities, RDAs, ARDA, business representative, academia and civil society, so they could provide significant inputs at different stages of the drafting process. Field assessment served to collect information and experiences from stakeholders as well as proved to be an opportunity to discuss the possible future scenarios for the framework of regional development. The results of the field work are explained later in the section on field work data collection and data analysis with findings.

\subsection{Identification of Regional Economic Development Competences and Needs}

Kosovo is a small country organized into two levels of governance. The municipalities according to the law have several very important competencies that can be better utilized if they are part of a broader regional dimension and business support. Such competencies are related to:

a. Local economic development

b. Urban and rural planning, land use, and development

c. Implementation of building regulations and building control standards

d. Local environmental protection

e. Provision and maintenance of public services and utilities, including water supply, sewers and drains, sewage treatment, waste management, local roads, local transport, and local heating schemes

f. Local emergency response

g. Provision of public pre-primary, primary and secondary education, including registration and licensing of educational institutions, recruitment, payment of salaries, and training of education instructors and administrators

h. Provision of public primary health care and public health

i. Provision of family and other social welfare services, such as care for the vulnerable, foster care, child care, and elderly care, including registration and licensing of these care center, recruitment, payment of salaries and training of social welfare professionals

j. Public housing

k. Licensing of local services and facilities, including those related to entertainment, cultural and leisure activities, food, lodging, markets, street vendors, local public transportation and taxis

1. Naming of roads, streets and other public places

$\mathrm{m}$. Provision and maintenance of public parks and spaces

n. Tourism and Cultural and leisure activities

Comparing the competencies of different governmental levels shows that there are huge possibilities for better strategic management and more supportive approach toward regional economic development in different sectors. There is the need to have common strategies and policies that can be implemented at the regional level such as business environment, employment, economic development, education, and social policy, among others. Regional planning and land management are pillars of economic development. A clear and defined plan can result in a relevant competitive advantage for economic development of the whole region. Regional planning and regional approach can stimulate the construction and infrastructure sector. There is a wide space for creating Public-Private Partnerships (PPPs) for the service management and same is possible for environment, education, and promoting cultural events and cross border exchanges that can be exceptional opportunities for doing business and supporting the economic activities within the country.

\section{Data Analysis}

For the purpose of evaluation of actual situation and for strategic approach alternative to be chosen, almost all stakeholders were visited and primary data information were collected. The identification of stakeholders to be interviewed is done based on overall inclusion of the parties. Below in the table are presented all interviewed representativeness from central government, local government, ARDA and RDAs, business association, Association of Kosovo Municipalities, civil society, and public Universities in respective regions in the country.

Table 2. List of stakeholders consulted and interviewed.

\begin{tabular}{llllllll}
\hline No. & Institution & No. & Institution & No. & Institution & No. & Institution \\
\hline 1 & MLGA & 8 & MESP & 17 & Association of Municipalities & 24 \\
2 & ARDA & 9 & Pristina Municipality & 18 & $\begin{array}{l}\text { Ministry of Economic } \\
\text { Development }\end{array}$ & Shtime Municipality & Mitrovica Municipality \\
\hline
\end{tabular}




\begin{tabular}{llllllll}
\hline No. & Institution & No. & Institution & No. & Institution & No. & Institution \\
\hline 3 & RDA East & 10 & Ferizaj Municipality & 19 & MTI & 26 & NGO Centre-CESD \\
4 & RDA West & 11 & Gjilan Municipality & 20 & Prime Minister Office & 27 & NGO South \\
5 & RDA South & 12 & Gjakova Municipality & 21 & Chamber of Commerce of & 28 & NGO North \\
6 & RDA Centre & 13 & Prizren Municipality & 22 & MEI & 29 & NGO East \\
7 & RDA North & 14 & Mitrovica North Municipality & 23 & Zvecan Municipality & 30 & University of Peja \\
& & 15 & NGO West & & & 31 & University of Pristina \\
\hline
\end{tabular}

Semi-structured interviews with open question during research were focused on the:

a. Verification of the efficiency and effectiveness of the current model based on its organisation, activities, business support, business satisfaction and potential to be used in the future.

b. Assessment of the situation with regard to regional economic cooperation and joint project development.

c. Functioning of the ARDA and RDAs in the specific regions, support, success, and failure cases on dealing with Regional Development projects including challenges and needs.

d. Common projects developed and implemented.

Below are figures showing the results and graphs that are showing the primary data analysis for the perception of RED in the country.

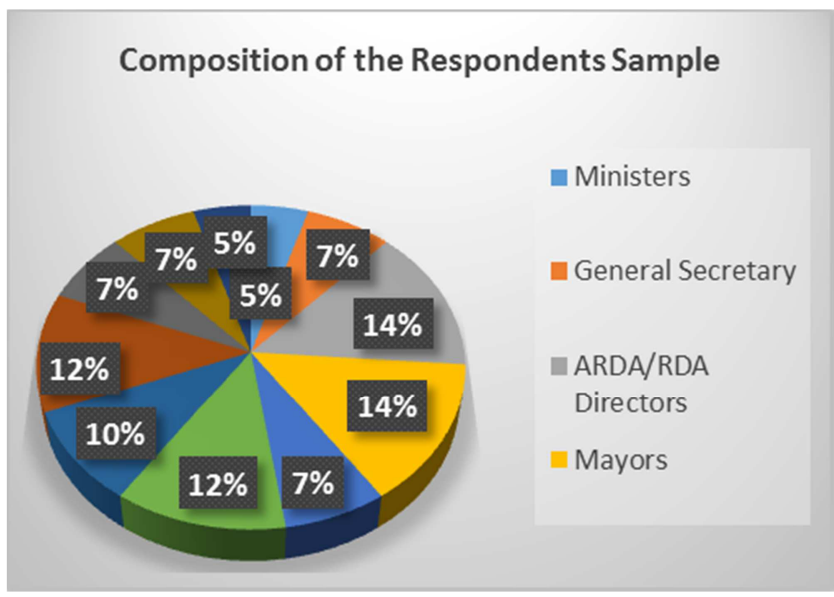

Figure 1. Composition of the respondent sample.

How satisfied you are with the current model of ARDA/RDAs and their work?

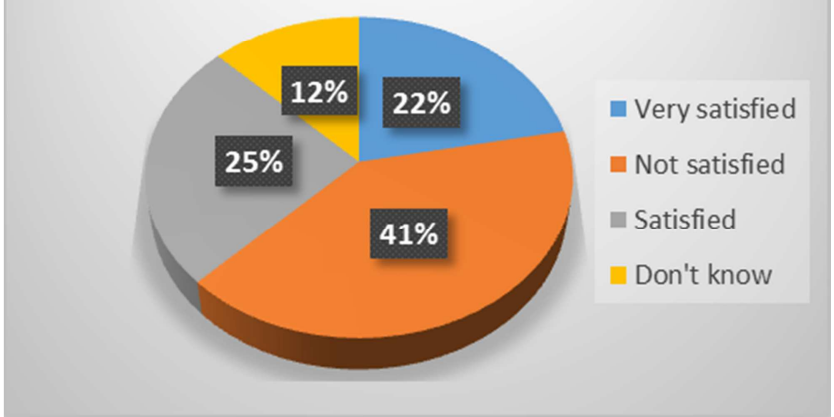

Figure 2. How satisfied you are with the current model of ARDA/RDAs and their work?

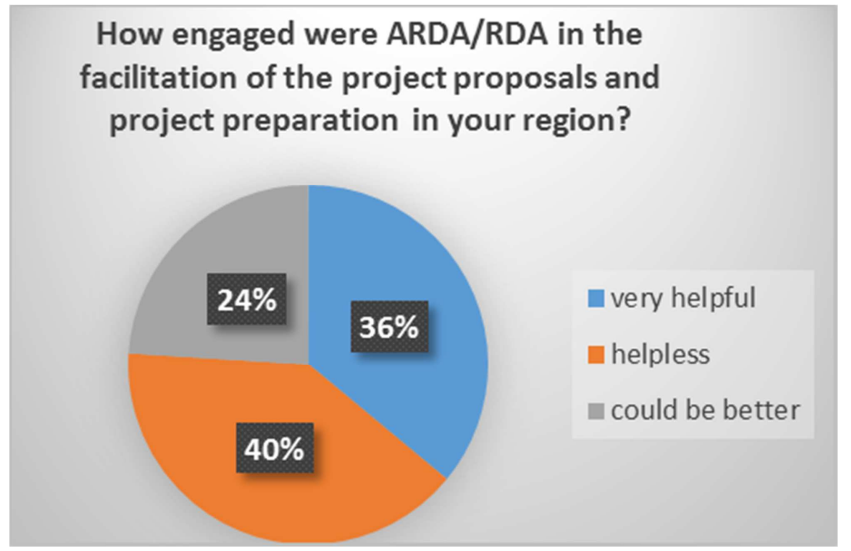

Figure 3. How engaged were ARDA/RDA in the facilitation of the project in your region?

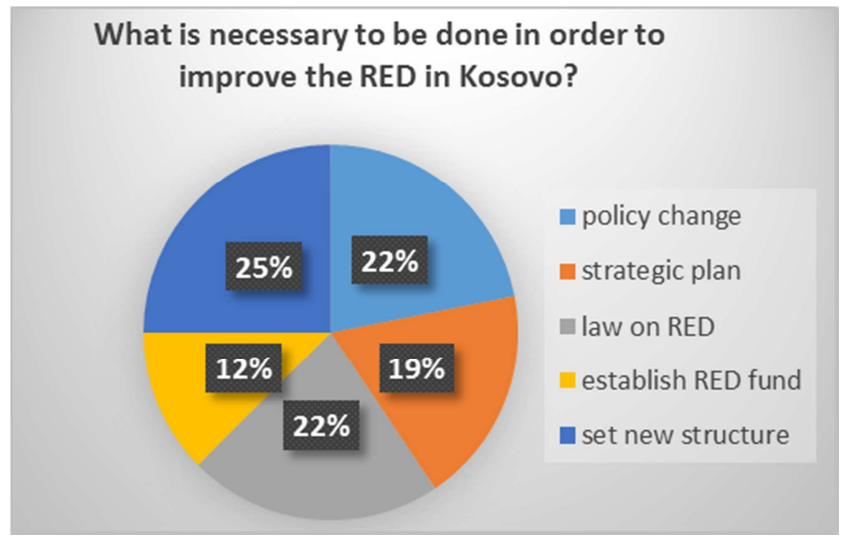

Figure 4. What is necessary to improve RED in Kosovo?

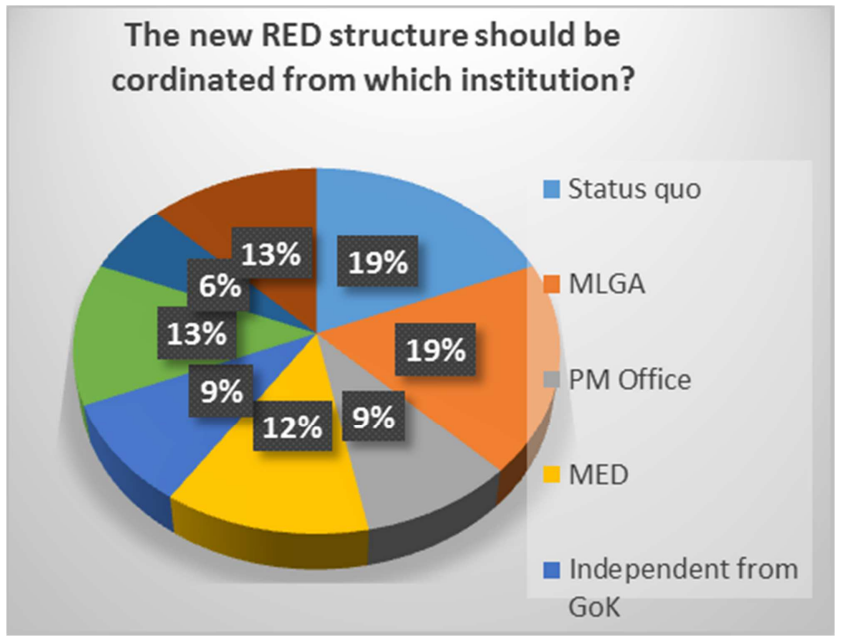

Figure 5. The new RED structure should be coordinated through which institution? 


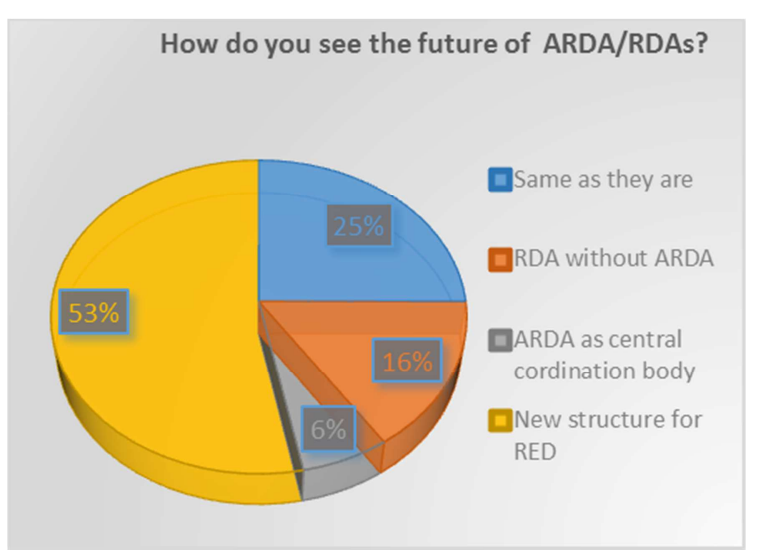

Figure 6. How do you see the future of ARDA/RDAs?

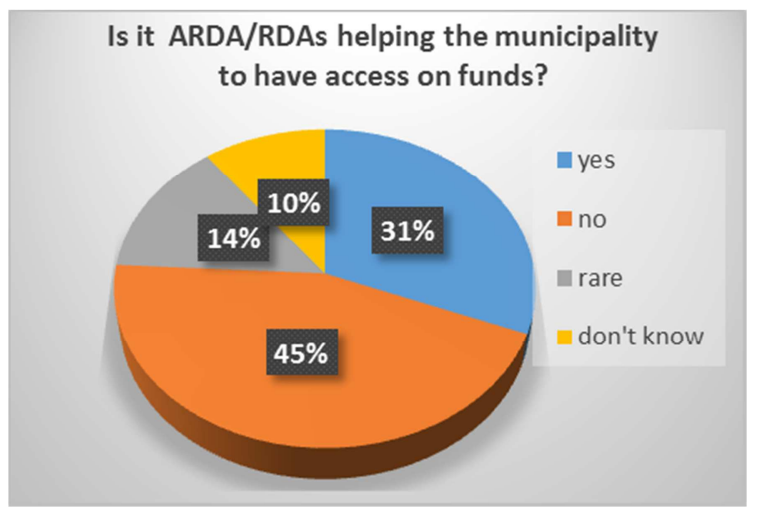

Figure 7. Is ARDA/RDAs helping the municipality to get access to funds?

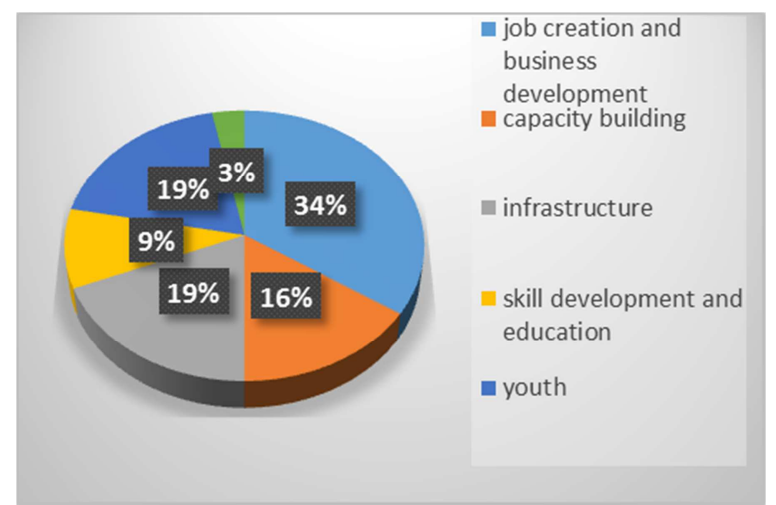

Figure 8. What are priorities that you want to be supported by ARDA/ RDAs?

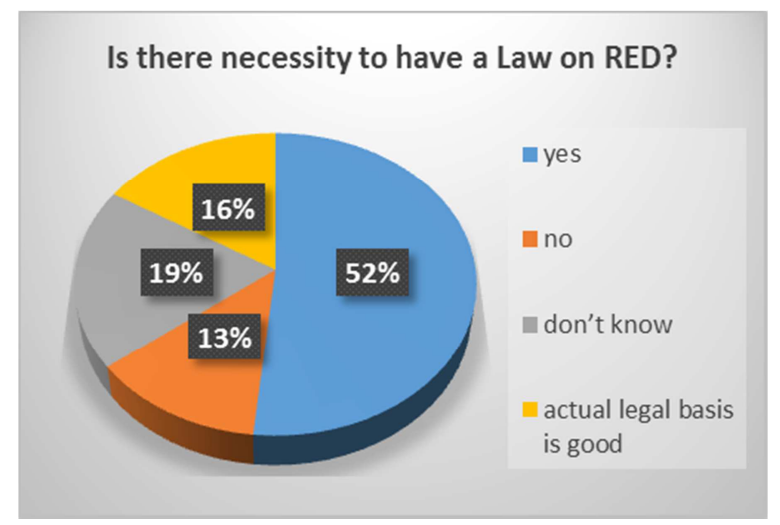

Figure 9. Is there necessity to have Law on RED?

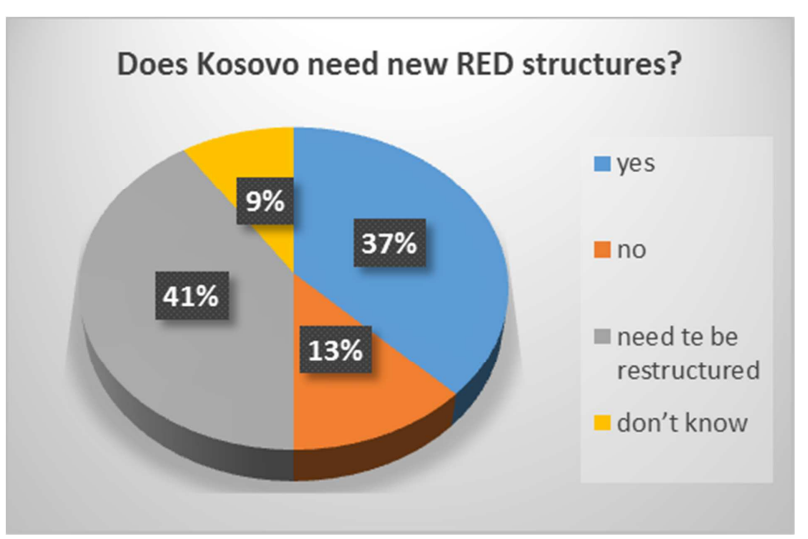

Figure 10. Does Kosovo need new RED structures?

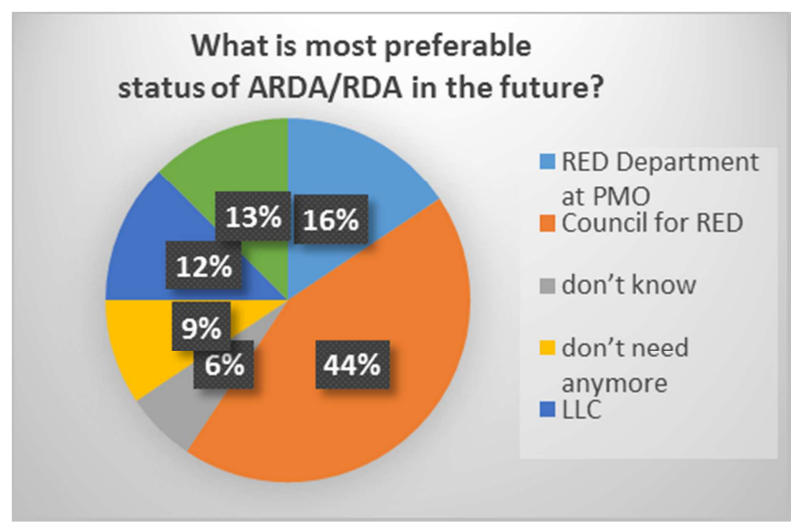

Figure 11. What is the most preferable status of ARDA/RDA in the future?

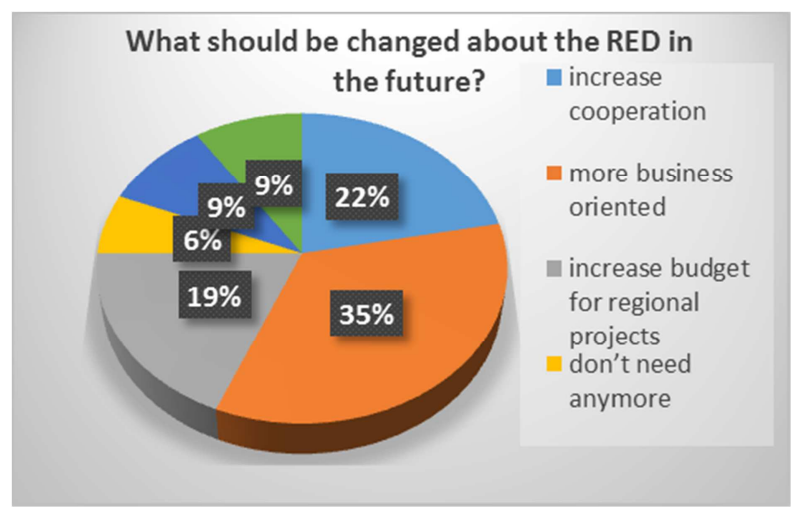

Figure 12. What should be changed about the RED's approach in the future?

Based on the figures above, at least three different groups of thoughts about the achievements, actual situation, and future developments are differentiated. The first group of identified stakeholders includes ARDA and RDA representatives, who describe the situation as good and they mainly listed activities and success.

They were not in all cases able to substantiate such thoughts with documentation and listed only the projects that have been realised according to them. To this group belonged some of the municipalities (Mitrovica, Mitrovica North, Zvecan, Gjilan and some of the civil society representatives, for example non-governmental organization (NGOs) in Gjilan, Peja and Mitrovica. 
The directors of RDAs provided the list of activities and projects they did in respective regions but in some cases the mayors did not recognised the same. Mostly the opinion of RDA representative's were based on number of grants and calls they launched or for which they provided information to regional stakeholders. This is well visible in the figures above, where the satisfaction of the respondents is not so high with the actual work and support done by RDAs and ARDA. However, it has to be recognised that grant schemes have not so far succeeded in contributing more significantly to the overall socio-economic development on local and regional levels. The RDA representatives, on the other hand, were not very satisfied with the status they actually have and ask for restructuring as a new legal entity that could as well take part in the project proposals as a partner, not just as a facilitator.

The second differentiated opinion is that RDAs have not been sufficiently involved so that they can exert a significant impact in their role as catalysts and initiators of local and regional development initiatives. This has weakened their position and biased the understanding of their real role and their visibility on a local and regional scale.

It is observed that the absence of tighter donor coordination and their willingness to support such synergies on the one hand, and, on the other hand, the poor capacity and inadequate positioning of the RDAs, could not offer a more solid leverage for needed synergies. Based on their mission, the RDAs support regional stakeholders in project identification and preparation. Therefore, the RDAs could help the potential applicants to specify different funding initiatives and to check their ideas against Regional Development Strategies and quality criteria for project selection. Most of the stakeholders from line ministries including MEI, MLGA, MEI, MESP; certain municipalities of Prizren, Ferizaj, and Gjakova; Universities; Association of Kosovo Municipalities; and business organisations share the common opinion that RDAs failed to play this role. This group expressed their dissatisfaction about the results of ARDA and RDA requiring the revision of the institutional framework of the RDA in the future.

MEI and MLGA in their union wanted to have more power in the regional coordination of funds and structures and, at the same time, they both do not see any role of ARDA in the future regional development policies. Meanwhile the Association of Kosovo Municipalities requests more inclusion in the regional development process since, in their opinion, they are more present in the regional development issues through their collegium of departments. The representatives from the academia have almost no contacts with RDAs and they were ready to help with their expertise in the possible new developments. Business representatives were not satisfied with the level of support from RDAs to businesses and wanted to have more space in any future structures along with an increase in business-oriented activities.

The third group includes the stakeholders without a clear opinion about RDAs and Regional Development. This, in particular, was case also with some ministries. In this group representatives of civil society in Pristina, Ferizaj and Gjakova are also present. Furthermore, they were very not well informed about the role and activities of RDAs. They recognized that there is room for improvement but did not recognize the need for capacity building as a way forward in Kosovo in order to have an effective and sustainable Regional Development Policy.

\section{Discussion, Findings and Evaluation of the Situation}

Regional Development Assessment in Kosovo shows that the situation is not satisfying for all relevant stakeholders as described above. The Association of Regional Development Agencies (ARDA) has evolved as an umbrella organization founded by the RDAs with the following objectives:

a. Coordinate the cooperation between the economic regions in Kosovo and respective Agencies.

b. Represent common and specific issues on the national level.

c. Attract financial resources on a national level to implement Regional Economic Development by promoting specifically Regional Rural Development.

d. Manage the knowledge and skills in RDAs for implementing common activities.

It would as such aim to develop a strong network with beneficiaries over time so that their needs would be addressed and supported in line with regional development policies promoting regional economic growth in Kosovo. It seems that neither the RDAs nor ARDA have achieved a satisfactory level of cooperation, either among them and/or with the local authorities and other development partners, including the concerned central government bodies.

It was evident during interviews with stakeholders and from observations during the visits that the cooperation between ARDA and the RDAs was not functioning at an optimum and that ARDA has had no presence and visibility at regional or even national level. According to the RDAs representatives, this is a result of the limitations in the range of RDAs' action, which have not been given the possibility to develop into a wider and deeper commitment in local and regional project developments. It is recognizable that they were constrained and have not been allowed to participate as applicants in any grant schemes. This formal constraint has dramatically limited their real capacity to be actors in local and regional development. Surely there are differences among regions and in the capacities of the RDAs' to effectively interact with stakeholders; but it has to be recognized that the RDAs provide valuable services in supporting grantees with the knowledge and expertise required to implement EU-funded projects. However, it seemed that, as time progressed, local authorities got more and more disappointed and many of them voiced the opinion that they did not really see how the RDAs were directly related to Regional Economic Development. As mentioned 
above, the approaches and results are varying among regions, but the common perception about ARDA is that it was not able to comply with its mission to evolve as a full-fledged organization with the capacity to promote vertical and horizontal complementarity and synergy as the current situation requires.

Moreover, as underlined above, the relatively narrow scope of responsibilities assigned to RDAs has had a direct effect by strongly reducing the potential field of synergy that could objectively have been developed. One distinct failing has been the lack of monitoring of the RDAs' activities, which could have supported subsequent synergies. Most of the interviewees at the central level still are not satisfied with actual organization. Moreover, the representatives of Universities and civil societies have not heard at all about ARDA or have not understood its real purpose and role.

\subsection{Strategic Scenarios for the Regional Economic Development}

The process of creating an integrated regional policy framework in completion of the National Development Plan should be in the agenda of the Government and of the Parliament of Kosovo. The policy - through a law or with a shared strategy - should aim toward:

(1)The reduction of the potential regional inequality, especially by stimulating balanced development and the revitalisation of marginalised areas (which have stagnated in their development).

(2)The increase of the competitiveness of regions by strengthening their capacity for innovation, optimal use and valorisation of the natural wealth, human capital and economic characteristics of different regions.

(3)The establishment of a mechanism to build solid linkages with government sectoral and development policies and activities at regional levels by stimulating the inter-regional, international and cross-border cooperation for economic development and welfare.

(4)The preparation of the institutional framework to meet the requirements of integration into EU structures and to ensure access to financial assistance instruments (IPA II, the structural funds and EU investments).

Different actors are involved on this matter. Regional Development sees the involvement of and requires coordination among different institutional levels for its governance. The approach on how coordination among different levels of engagement is achieved can be summarised into three possible alternatives. The scenarios described below consider the how Regional Development can be designed and implemented and then in which way the responsibility and the commitments are distributes among the different levels.

The first scenario envisages a balanced distribution of responsibilities between the central government and the territorial levels. The second considers the possibility for the central government to delegate part of its proper functions to the regions and as they are not administrative units, this delegation should be carried out through a positive and effective cooperation among the municipalities and with the assistance of dedicated agencies. The third scenario considers the possibility of a centralised mechanism for Regional Development where the Central Government designs, plans and implements, with a certain grade of consultation and involvement of local levels, a regional development strategy allocating funds using the fiscal lever, promoting projects, and favouring the development of social services and infrastructures.

\subsection{Regional Economic Development Scenarios}

a. Scenario 1- Balanced Regional Development

It concerns an institutional framework that clearly indicates the role and responsibilities of each level of the regional development value generation. The legal framework establishes a mechanism of coordination among the line ministries at the central level. At the local level, a specialised body or regional development agencies coordinates, promotes, and implements regional development projects with the active involvement and participation of the regional stakeholders into a clear partnership framework. Central Government acts as facilitator, coordinator, and controller of the mechanism to guarantee that the disparities are addressed through the efficient use of the resources. The central level provides resources, information, know-how and technical assistance for the effective design of the actions to achieve regional development goals. The local administrations actively cooperate to achieve the necessary critical mass to face the development challenges building partnerships and establishing an entity (like RDA) to concentrate the knowhow for regional development. This scenario implies a substantial coordination among the different actors both vertically and horizontally. More than the other two approaches, this setting needs a clear institutional framework for functioning but, if properly designed and when full commitment is received at all levels, it is able to generate the best results. It is the scenario where the power of partnership and sharing can lead to the success of regional development.

b. Scenario 2 - Bottom-up Regional Development

The central government indicates the general guidelines and the main expected achievements (as for Kosovo the National Development Plan) and the local level articulates its action for development based on their perceived needs. The process can be assisted by a specialised agency, wherein the capacities and the responsibilities from planning and implementing regional development projects and initiatives.

Regional development in Kosovo actually falls in this scenario. Due to the lack of a legal framework, municipalities have applied the general principle of subsidiarity. According to the Law on Local Self Government, each municipality is responsible for local development. Recognizing development as an intermunicipal dimension, RDAs and later ARDA have been established, which is a devolution of power but without a process of negotiation and established setting. In fact, most of the stakeholders accounted for a not clear definition of an 
appropriate institutional framework as the basis for acting appropriately on regional, projects and interventions. Leaving the situation as it is, the Inter-Municipal Cooperation Law could offer the basis for the coordination of activities for regional development in which RDAs could continue to play their role with or without the endorsement and the necessary support of the central government.

MLGA remains the institution which, to a small extent, coordinates policy development process for regional development, in cooperation with line ministries and their agencies as defined by the Regulation No. 09/2013 which in Article 9 states "The entire process of inter-municipal cooperation and regional socio-economic development of municipalities shall be coordinated by the Ministry of Local Government Administration.

c. Scenario 3 - Top - Down Regional Development

The scenario envisages the creation of a mechanism at the central level to coordinate activities with the line ministries and provide the legal framework for regional development. The Office of the Prime Minister could play a leading role in assessing regional development policy and ensuring the legal framework for better coordination of activities. Government takes ownership of socio-economic development with the establishment of a national body (agency or inter-ministerial committee) and regional branches deputed to implement policies and actions set out at the central level. The central government establishes the mechanisms and creates the structures for the dialogue with the regional actors. It decides the allocation of funds and the priorities in the different regions according to the National development Plan and the Sectorial Development Plans. It also establishes the grade of decision-making for the local authorities in the range from consulting to implementing partner.

In Kosovo, some active national agencies are already involved in projects and activities related to Regional Development implementing sectorial development plans. The Ministry of Trade and Industry has seven active agencies with regional offices and 28 one-stop shops in many municipalities that could take the responsibility for regional economic development, while the other line ministries could cooperate in order to establish a coordination unit at central level.

This scenario would see RDAs as direct emanation of the central government as agencies under the Office of the Prime Minister or of the MLGA. RDAs based at the regional level or a National Regional Development Agency would respond directly to the Central Government's negotiating strategies, plans and actions with the municipalities and the regional stakeholders concordant with modalities established at Government Level.

The three scenarios can be combined in different nuances according to the grade of application of the policy principles indicated above. In particular, the policy addresses who at which level elaborates plans and sets out priorities, concentrating the resources on a specific set of objectives for both national and regional level.

\section{Conclusion}

While strategic and coherent planning at all levels is a vital first step, even the best plans are worth little without good governance. Governance means performance and success of development policies and governance of regional development strategy means building a strong and long lasting partnership among the actors at all levels. Regional engagement assists successful regional development policymaking, programme design and management, and service delivery activities. It underpins Government's commitment to local challenges, engaging with local government, local businesses and citizens and achieving long-lasting change and reforms. Regional actors provide important local information, evidence, data and potential solutions. This enables government to have a better understanding of where a region is, where it wants and needs to go in the future, and how it intends to get there.

\section{Recommendations}

All tiers of government need to consider promoting alignment, close working relationships, cooperative regional planning, and joint membership with regional actors helping them to grow and increase their skills for a better and more effective action for development. Government linked with regional entities can have a cumulative effect of expanding the engagement of local actors, especially when there is a clear understanding of government processes relating to policy-making, investment, and decision-making, thus generating multiplying effects on the interventions' outcomes. There are three steps that paper recommends to the responsible institutions to be undertaken.

Firstly, it needs to launch the process for designing a common balanced framework for Regional Development. The framework for the Regional Development Policy should be the result of a dialogue among the central government, the municipalities, the RDAs, and the regional actors. This process of involvement and negotiation among the parties has to be part of the strategy and a precondition for the achievement of a Balanced Regional Economic Development Strategies and Policy, which aims to reduce the existing regional disparities and prevent further regional imbalances.

The establishment of thematic working groups to address the challenges and elaborate the new framework is a good practice for collecting information, receiving feedback, and recommendations to elaborate the Regional Development Framework.

An inter-ministerial task force coordinated by the Office of the Prime Minister could organize the process, collect the inputs, and elaborate the draft of the Regional Development Framework for the endorsement of the parties involved.

Secondly, following the negotiation process, the Government of Kosovo should elaborate the legal framework for regional development and submit it for the approval. The provision of a regional economic development law is the best arrangement for a long lasting commitment and a transparent 
and binding mechanism for the central and local level on regional development. The law should envisage the following aspects:

a. Responsibilities and rights of State Administration, private sector and the local governments

b. Bodies and authorities involved on regional economic development policy and strategic planning

c. Planning of development steps (formulation) and planning system

d. Approval mechanisms of policy and strategic documents

e. Making changes and amendments in such documents f. Monitoring and evaluation of development strategy

g. Ensuring overall participation and transparency in planning activities

h. Financial provision for the implementation and the functioning of the Regional Economic Development Fund

i. Sanctions for violations of the legislation.

Thirdly, the Government of Kosovo should design the perimeter in which regional development should take off, starting from the experience made in the first years with RDAs and the support provided by the Ministry of Local Government Administration (MLGA).

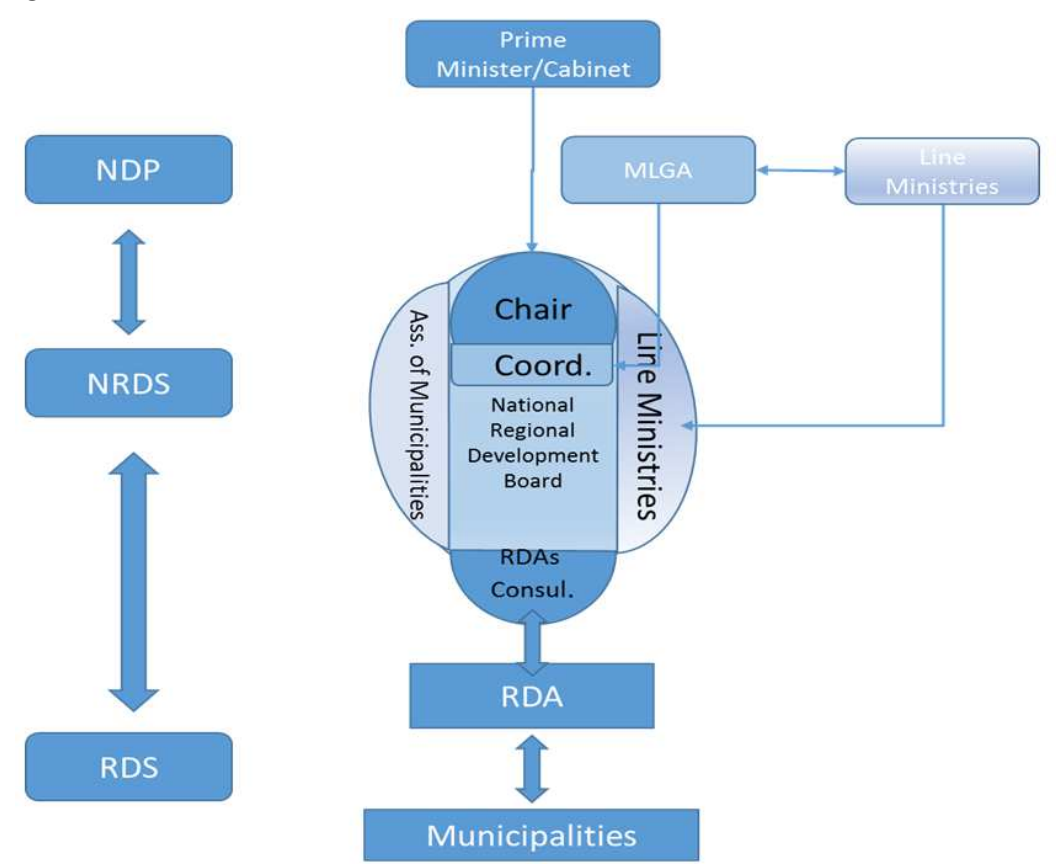

Legend:

NDP-National

development policy

NRDS- National

regional

development

strategy

RDS-Regional

development

strategies

MLGA-Ministry of

local government

administration

Figure 13. Strategic model for regional economic development-institutional framework.

Once that the framework has been set out, the MLGA should make an assessment of regional development capacities at regional and municipal level, and subsequently launch capacity building interventions to improve the capacities of municipalities to positively approach the new model and to contribute in the design, elaboration and implementation of the regional development strategies and in the empowerment of the RDAs to deal with their new mandate.

Central to this approach is the enhancement of the ability of businesses and communities to identify problems and issues, set goals and objectives, and develop and implement strategies and initiatives in order to take charge of their own development. Skills need to be enhanced in the following areas:

a. The capacity to address simultaneously a range of issues rather than a single concern; breaking down the artificial boundaries and compartmentalisation that characterize the ways that governments generally tackle social and economic issues.

b. Encourage partnerships and collaborative working arrangements across economic sectors and among government, community, private, voluntary, educational and other partners, and require new forms of multi-level governance.

c. To enhance inclusiveness, involving all segments of society and the community in identifying and working on solutions.

d. Management of project and initiatives in the long-term as they are developmental in nature, seeking to build capacity and structures in the community and mobilize community resources to foster social and economic.

e. Approach development and sustainability rather than making remedial spending interventions to reduce or compensate for specific identified problems.

\section{References}

[1] Ascani, Riccardo Crescenzi, Simona Iammarino. January 2012, "Regional Economic Development", SEARCH WP01/03, InteRregionally Cohesive Neighborhoods (SEARCH) within the 7th European Community Framework Programme FP7-SSH -2010. 2.2-1 (266834) European Commission. 
[2] Bachtler, J. \& Wren, 2009, C. "Evaluation of European Union Cohesion policy: Research questions and policy challenges". Regional Studies, 40: 143-153.

[3] Barca, F. 2009, "An agenda for a reformed Cohesion Policy: A place-based approach to meeting European Union challenges and expectations. Independent report, prepared at the request of the European commissioner for regional policy".

[4] Roberta Capello, 2009. "Theories: Conceptual Evolution over Fifty Years of Regional Science, Dans Géographie, économie, société 2009/1 (Vol. 11), pages 9 à 21".

[5] Carlino, G. A., Chatterjee, S. and Hunt, R. M. 2001, Knowledge Spillovers and the New Economy of Cities, Economic Research Division, Working Paper No. 01-14, Federal Reserve Bank of Philadelphia, PA.

[6] Riccardo Crescenzi, Andrés Rodríguez-Pose, Michael Storper, 2007, "Journal of Economic Geography", Volume 7, Issue 6, Pages 673-709, https://doi.org/10.1093/jeg/lbm030

[7] Danuta Hubner, European Commission, Brussels, EU Regional Development Strategy, 2016, Brussels.

[8] EURED Report, 2017, Pristina.

[9] H. W. Richardson, 1973, "Regional Growth Theory", London: MacMillan.

[10] Hirschman, A. O. 1958, "The Strategy of Economic Development". Yale University Press.

[11] http://mzhe-ks.net/en/economic-development-and-europeanintegration

[12] Kosovo Economic Profile-CIA, 2017.
[13] Lewis, W. A, 1955, "Theory of Economic Growth", Homewood, Illinois.

[14] J. Niskanen, 2007, "The Determinants of Firm Growth in Small and Micro Firms - Evidence on Relationship Lending Effects", University of Eastern Finland, Finland.

[15] M. Kosecik, I. Sagbas, 2007, "Public attitudes to local government in Turkey: research on knowledge, satisfaction and complaints", Local Government Studies 30 (3), 360-383.

[16] National Development Strategy of Kosovo 2016-2021, Pristina, 2016.

[17] Nurkse, Ragnar. 1963, "Problems of Capital Formation in Underdeveloped Countries", Oxford.

[18] Seitovsky, Tibor. 1954, "Two Concepts of External Economies”, Journal of Political Economy, April, 1999.

[19] Porter, Michael, 1998, “On Competition". Boston: Harvard Business School Press.

[20] Rosenstein-Rodan, Paul N. 1943, "Problems of Industrialization of Eastern and Southeastern Europe", Economic Journal, June-September; and Notes on the Theory of the Big Push (mimeographed 1957).

[21] Rodriguez-Pose, A. and Fratesi, U. (2004) Between development and social policies: the impact of European Structural Funds in Objective 1 regions, Regional Studies, 38 (1): $97 a ̂ 113$.

[22] Yuill, D. et al. 2008, "New Policy Frameworks, New Policy Approaches: Recent Regional Policy Developments in the EU and Norway", EoRPA Paper 08/1. 